\title{
ASPECTOS GERAIS DO BEM DE FAMÍLIA LEGAL
}

\author{
LEGAL ASPECTS OF THE HOMESTEAD
}

Saulo de Oliveira Salvador Junior ${ }^{1}$

\begin{abstract}
Resumo: O presente trabalho tem como objetivo discutir o instituto do Bem de Família legal, ou compulsório, instituído pela Lei 8.009/90. Para tanto, aborda-se, inicialmente, sua origem histórica, as espécies existentes no ordenamento jurídico brasileiro, conceito, natureza jurídica, constitucionalidade da citada lei, análise de seus requisitos, abrangência e casos em que o instituto não é reconhecido por existir exceção legalmente estabelecida. A pesquisa é bibliográfica, com finalidade descritiva e exploratória, mediante análise da legislação nacional, sua interpretação doutrinária e aplicação pelos tribunais. Conclui-se que é um importantíssimo instrumento de garantia de direitos fundamentais da entidade familiar, sem, no entanto, deixar de ser aplicado em exceções previstas em lei.
\end{abstract}

Palavras-chave: Direito Civil, Bem de Família Legal, Impenhorabilidade

\begin{abstract}
This paper aims to discuss the institute of the homestead established by Law 8.009/90. To do so, it initially addresses its historical origin, the species existing in the Brazilian legal system, concept, legal nature, constitutionality of the aforementioned law, analysis of its requirements, scope and cases in which the institute is not recognized because of the legal exceptions. The research is bibliographic type, with descriptive and exploratory purposes, through analysis of national legislation, its interpretation and application by the courts. The homestead is an extremely important instrument for guaranteeing fundamental rights of the family entity, without, however, failing to be applied in the legal exceptions.
\end{abstract}

Keywords: Private law, Homestead, Unseizability

\section{Introdução}

Diante da complexidade das relações sociais, notadamente das relações obrigacionais, as quais uma vez inadimplidas podem, via de regra, culminar na execução do devedor com a consequente excussão forçada de seus bens, urge que o Estado crie meios de assegurar a garantia de alguns direitos fundamentais. Neste contexto, o desafio está em, ao mesmo tempo, garantir a eficácia do crédito e proteger o devedor em algumas situações para que não tenha direitos fundamentais atingidos.

Sem pretender esgotar o tema ora proposto, o objeto do presente estudo é analisar de maneira geral a Lei 8.009/90, que introduziu este importante instituto de proteção à propriedade familiar, o que engloba o direito à moradia e garantia do mínimo existencial.

\footnotetext{
${ }^{1}$ Mestrando em Função Social do Direito - Faculdade Autônoma de São Paulo (FADISP).

E-mail: sauloosjr@gmail.com
} 
Com origem no direito norte americano, no início do século XIX, numa época de crise econômica e de incentivo político de povoamento de áreas inabitadas do território daquele país, chegou ao ordenamento jurídico brasileiro somente no ano de 1916, com a entrada em vigor do antigo Código Civil, que previa somente a espécie de instituição voluntária, vindo a ter tratamento ampliado e previsão da espécie de interpelação automática somente no ano de 1990, com a Lei 8.009. Logo, surgiram questionamentos a respeito da constitucionalidade da citada Lei, notadamente quanto sua aplicação às execuções já em curso, prevalecendo sua vigência plena e o entendimento de que ela não feriria os preceitos constitucionais da sujeição patrimonial e da irretroatividade legal.

Ao pôr o imóvel de residência familiar a salvo da execução por dívidas contraídas pelos membros da família, o bem de família legal mostra-se como um importante instituto de concreção do direito fundamental ao mínimo existencial, à moradia e, consequentemente, de garantia de dignidade, sendo certo que para seu reconhecimento nos autos de execução, basta serem demonstrados os requisitos da propriedade e residência no imóvel. Afirmando, ainda, o nítido caráter de proteção familiar do instituto, a impenhorabilidade vai além do único imóvel de residência da família, abrangendo também móveis que o guarnecem.

Todavia, dado o caráter relativo dos direitos fundamentais, a impenhorabilidade do bem de família também não é absoluta. Na maior parte desta pesquisa, sob esta ótica, serão abordadas as hipóteses em que há exceção à mencionada impenhorabilidade, prevalecendo outros direitos em detrimento dos que fundamentam o instituto, como em casos de ações movidas em decorrência de créditos para aquisição do próprio imóvel, de pensão alimentícia, cobrança de impostos relativos ao prédio, dentro outros adiante analisados.

\section{Referenciais Históricos do Bem de Família}

Diferentemente da maioria dos institutos jurídicos do direito privado, o bem de família não teve sua origem no Direito romano, muito embora há quem sustente terem existido institutos que seriam seu verdadeiro "embrião", como a proibição de alienar o patrimônio familiar, que decorria do caráter sagrado dos bens herdados dos antepassados, o instituto da adrogação, o benefício da competência e o fideicomisso. Os institutos citados demonstram ${ }^{2}$ que a preocupação com a proteção dos bens pertencentes ao conjunto familiar já existia naquele sistema normativo, apesar de diferente do bem de família previsto em nosso sistema atual, muito

\footnotetext{
${ }^{2}$ AZEVEDO, Álvaro Villaça. Bem de Família. 6. ed. São Paulo: Atlas, 2010
} 
pelo fato possuir somente um viés patrimonial, não priorizando a proteção do núcleo familiar, como hoje se apresenta.

Pacífico é que o bem de família nos moldes atuais foi primeiramente instituído na República do Texas. No início do século XIX, os Estados Unidos, recém separados da Inglaterra, sofriam com uma crise que proporcionou a quebra de diversos estabelecimentos. Aproximadamente mil bancos fecharam e as famílias, sofrendo com as execuções das dívidas vencidas, necessitavam de uma legislação que as socorressem. Foi então que em 1839, no Estado do Texas, antes de sua anexação aos Estados Unidos da América, foi promulgado o Homestead Exemption Act ${ }^{3}$.

Com o objetivo de fixar as famílias na região, este ato normativo garantia a cada cidadão determinada porção de terra, deixando-as livre de eventual excussão forçada. Ao lado de seu intuito político e social, surgiu, desta maneira, como forma de garantir o abrigo familiar, e, em pouco tempo, se espalhou pelo território dos Estados Unidos e transcendeu suas fronteiras, sendo adotado por outros países e por outros povos, com as devidas adaptações.

No Brasil, o bem de família teve sua primeira aparição no Código Civil de 1916. Embora o instituto não constasse do projeto de Clóvis Beviláqua, foi inserido por emenda proposta pelo Senado Federal, na Parte Geral do citado diploma legal, entre os artigos 70 a 73, o que não agradou aos juristas, dado o caráter claramente familiar do instituto. Mais adiante, foram editados decretos estabelecendo limites aos valores da instituição do bem de família. Em 1973, a Lei 6.015, Lei dos Registros Públicos, estabeleceu o trâmite de sua constituição.

A Lei 8.009 de 29 de março de 1990 institui no ordenamento pátrio o hoje chamado bem de família legal e a reforma do Código Civil de 1916 realocou o bem de família de constituição voluntária na parte especial do Codex, no livro de direito de família, vigorando até o ano de 2002, quando o novo Código Civil entrou em vigor, trazendo novas regras para sua constituição voluntária sem, no entanto, revogar a Lei 8.009/90.

\section{Espécies de Bem de Família, Conceito e Natureza Jurídica}

Há, portanto, duas espécies de bem de família no ordenamento jurídico brasileiro: o voluntário e o legal, valendo ressaltar que as duas categorias não se confundem, não havendo antinomia entre elas, pelo fato de possuírem arcabouços jurídicos distintos.

O bem de família voluntário, disciplinado entre os artigos 1.711 e 1.722 do atual Código Civil, é instituído por ato de vontade, através instrumento público levado a registro imobiliário,

\footnotetext{
${ }^{3}$ VENOSA, Sílvio de Salvo. Direito civil: direito de família. 12. ed. São Paulo: Atlas, São 2012. v. 6.
} 
pelo qual o bem é destacado do patrimônio familiar gerando dois efeitos principais: impenhorabilidade por dívidas futuras e inalienabilidade do referido bem. Em linhas gerais, há um limite no valor de sua constituição, que só pode ser feita em favor de entidades familiares, sendo também possível, em grande novidade legislativa, que seja composto por valores mobiliários. Nesta linha, conclui-se que a natureza jurídica do bem de família voluntário é de um patrimônio afetado ${ }^{4}$, o qual não será atingido por futuras execução, embora também não poderá ser alienado sem autorização judicial.

Nas palavras de Sílvio de Salvo Venosa, “(...) apesar da difusão, o sucesso da instituição não alcançou a dimensão esperada, mormente em nossa pátria, onde sua utilização voluntária é diminuta". Mais adiante, na mesma obra, o autor ainda afirma que o instituto se tornou inútil pelo fato da Lei 8.009/90 suprir a proteção que o núcleo familiar necessita, tanto que o Projeto do Estatuto das Famílias o suprime. ${ }^{5}$

O bem de família legal, também chamado de bem de família compulsório ou obrigatório, disciplinado pela Lei 8.009/90, cujo artigo $1^{\circ}$ o define como sendo imóvel residencial próprio do casal, ou da entidade familiar, sendo impenhorável e não responsável por qualquer tipo de dívida civil, comercial, fiscal, previdenciária ou de outra natureza, contraída pelos cônjuges ou pelos pais ou filhos que sejam seus proprietários e nele residam, salvo nas hipóteses previstas na citada lei.

Extrai-se, desta forma, que esta espécie é caracterizada por um bem ou conjunto de bens impenhoráveis, ou seja, bens aos quais a lei confere proteção especial, não permitindo a penhora e expropriação para o pagamento de dívidas, salvo algumas exceções. O bem de família, por esta lei, é contemplado de forma mais ampla e facilitada, pois não é necessário a constituição por escritura pública, nem registro imobiliário, tampouco o bem fica fora do comércio. Sua natureza jurídica consiste em ser um bem impenhorável.

O instituidor é próprio Estado, que impõe o bem de família através de norma de ordem pública, buscando proteger a unidade familiar. O objeto é o imóvel, urbano ou rural, destinado a moradia da família, e o móveis que o guarnecem.

Certo é que, para ambas as espécies, a proteção conferida pela citada Lei 8.009/90 ampara-se no direito constitucional à moradia e, em nível doutrinário, na tese de Luiz Edson Fachin, intitulada O Estatuto Jurídico do Patrimônio Mínimo, segundo a qual, à luz do princípio

\footnotetext{
${ }^{4}$ PEREIRA, Caio Mario da Silva. Instituições de Direito Civil. 12. ed. Rio de Janeiro: Forense, 1991.

${ }^{5}$ VENOSA, Sílvio de Salvo, Direito civil: direito de família. 12. ed. São Paulo: Atlas, 2012.
} 
da dignidade da pessoa humana, as normas civis devem resguardar a cada pessoa o mínimo de patrimônio para que tenha vida digna.

\section{Constitucionalidade da Lei 8.009/90}

A Lei 8009/90 é proveniente da conversão em lei da Medida Provisória n 143 de 1990, em 29 de março do mesmo ano, e, pelo alcance normativo e peculiaridades, notadamente sua aplicação nos processos em curso (artigo $6^{\circ}$ ), muitas foram as discussões a respeito da sua constitucionalidade.

Formou-se corrente a favor da inconstitucionalidade sustentando que deixar bens a parte de execuções por dívidas feriria o princípio da sujeição patrimonial insculpido no artigo $5^{\circ}$, incisos LXVII e LIV da Constituição Federal, além de, indo mais a fundo, não estar de acordo com regime econômico adotado pela Carta Magna, pois suprimiria garantias e, desta forma, não haveria uma eficácia coativa do direito ao crédito.

Entretanto, o debate está superado e, atualmente, é pacifica a posição que pugna pela constitucionalidade da Lei, tendo em vista que esta ampliou a proteção conferida pelo então Código Civil vigente. Entende-se que a garantia do abrigo familiar decorre da dignidade da pessoa humana que impõe um mínimo existencial à família e prevalece sobre a ideia de que todos os bens do indivíduo devem responder por deus débitos, evidenciando, desta maneira, o caráter social de nossa Constituição, confirmado pela Lei instituidora do bem de família.

A discussão surgiu da infeliz redação do artigo $6^{\circ}$, in verbis: "São canceladas as execuções suspensas pela Medida Provisória n 143, de 8 de março de 1990, que deu origem a esta lei".

De início, podemos afirmar que a interpretação literal do dispositivo nos evidencia a sua flagrante inconstitucionalidade ao determinar a extinção das execuções, visto que não é função de lei extinguir ação que envolve direito a ela pré-constituído em título ao qual o diploma processual civil confere força executiva. Entretanto, a intenção do legislador foi outra: a aplicação imediata da lei com o cancelamento das penhoras, o que é muito diferente da extinção de execuções em curso. Estas continuariam a existir, resguardado o direito de crédito e de sua respectiva ação de execução, podendo ser penhorados outros bens do devedor.

Mesmo com esta adequação da exegese normativa, mais um problema é trazido a discussão: haveria desrespeito ao princípio da irretroatividade das leis, consagrado no artigo $5^{\circ}$, XXXVI, da Constituição Federal, pelo qual "a lei não prejudicará o direito adquirido, o ato jurídico perfeito e a coisa julgada". Assim sendo, duas correntes se formaram com ampla 
sedimentação jurisprudencial e doutrinária. A primeira com fundamento em que a penhora já realizada seria um ato jurídico perfeito e, desta forma, inconstitucional a lei. E a segunda, para a qual os atos de penhora não confeririam aos seus titulares direito adquirido, tendo a dita lei efeitos retroativos, sem ferir seu parâmetro constitucional.

Pois bem, a divergência foi intensa e podemos nos deparar com inúmeros posicionamentos a respeito do tema. Todavia a discussão foi sepultada pela edição da Súmula 205 do Superior Tribunal de Justiça, consolidando o entendimento a favor da constitucionalidade da Lei 8.009/90 e de seu efeito retroativo, segundo a qual "a Lei 8.009/90 aplica-se à penhora realizada antes de sua vigência”. É o entendimento acertado, vez que, sendo considerada como norma de ordem pública, é dotada de retroatividade motivada, conforme regra de direito intertemporal estabelecida no art. 2.035, do Código Civil.

\section{Requisitos do Bem de Família Legal}

Para que seja reconhecido o bem de família, na fase de execução, antes da arrematação do bem, deve ser demonstrado nos autos, por simples petição, como se extrai do art. $1^{\circ}$, da Lei 8.009/90, que o imóvel é próprio da entidade familiar e que seus membros nele residam. Temos então, dois requisitos básicos: propriedade do casal ou entidade familiar e que utilizem o imóvel para sua residência.

Quando a lei menciona casais está se referindo aos cônjuges. A entidade familiar tem o significado extraído dos parágrafos $1^{\circ}, 3^{\circ}$ e $4^{\circ}$ do art. 226 da Constituição da República: a família decorrente do casamento civil, a união estável e a família monoparental.

Entretanto, prevalece o entendimento doutrinário e jurisprudencial que o rol constitucional familiar é exemplificativo, sendo admitidas outras manifestações familiares, como a entidade familiar anaparental, a homoafetiva e a mosaico. Desta forma, devemos levar em conta que entidade familiar é uma comunidade formada por indivíduos que são ou se consideram aparentados, unidos por laços naturais e/ou afetivos.

Esta é a definição de entidade familiar que mais se harmoniza com o intuito da Lei 8.009/90, pois visa à proteção do patrimônio mínimo e ao direito à moradia da entidade familiar. Neste prisma, o STJ editou a Súmula 364 que estende a garantia do bem de família aos solteiros ou pessoas que vivem solitariamente, pois não podem ser alijados da proteção só por viverem sozinhos, uma vez que a interpretação social da norma ora em estudo é, de fato, resguardar o mínimo existencial e garantir um teto para cada pessoa. 
Pois bem, visto quem será beneficiado pelo instituto, cumpre-nos elucidar que o imóvel deve ser destinado à residência destas pessoas, ou seja, o casal ou os membros da entidade familiar devem utilizar o imóvel como sua moradia permanente, como dispõem os artigos $1^{\circ}$, caput, e $5^{\circ}$, in fine, da Lei 8.009/90. Assim, imóvel residencial é o que serve de local (elemento objetivo) para que se estabeleça uma família, centralizando suas atividades, com vontade de ali permanecer (elemento subjetivo), podendo ser considerado um verdadeiro domicílio familiar.

Este requisito é muito importante e, no intuito de dar maior amplitude possível à proteção conferida pela Lei 8.009/90, o STJ vem considerando que, mesmo o proprietário, aquele que consta da matricula do imóvel, não residir nele, mas residindo um familiar, deve incidir a impenhorabilidade ora tratada (STJ, EREsp 1.216.187/SC, Rel. Min. Arnaldo Esteves Lima, j. 14/05/2014). Nestes casos, a residência pode ser comprovada pelos mais diversos meios de prova, como comprovantes de pagamentos de contas de água, luz, gás e telefone, condomínio, tributos incidentes, testemunhas, dentre outros.

Por fim, vejamos o teor da Súmula 486 do STJ: "É impenhorável o único imóvel residencial do devedor que esteja locado a terceiros, desde que a renda obtida com a locação seja revertida para a subsistência ou a moradia da sua família”. A flexibilização do requisito deve ser vista com bons olhos.

Trata-se do chamado bem de família indireto, sendo uma forma de proteger o patrimônio mínimo de muitas entidades familiares brasileiras que locam um imóvel e destinam os frutos para a própria subsistência e, até mesmo, para locação de outro imóvel de menor valor. Vale destacar que a Corte Superior entende, segundo o mesmo raciocínio, que a premissa deve ser estendida para o caso de o único imóvel esteja dado em usufruto a mãe do proprietário (STJ, REsp 950. 663/SC, 4ª Turma, Rel. Min. Luis Felipe Salomão, j. 10/04/2012).

\section{Abrangência do Bem de Família Legal}

Nos termos do parágrafo único, do artigo $1^{\circ}$, da Lei em estudo, “A impenhorabilidade compreende o imóvel sobre o qual se assentam a construção, as plantações, as benfeitorias de qualquer natureza e todos os equipamentos, inclusive os de uso profissional, ou móveis que guarnecem a casa, desde que quitados".

A impenhorabilidade recai sobre o único imóvel utilizado pelo casal ou entidade familiar, para moradia permanente, sendo que, se houver vários imóveis da mesma natureza, recairá sobre o de menor valor, exceto se outro tiver sido instituído como bem de família voluntário. Esta é a regra extraída do art. $5^{\circ}$, caput e parágrafo único, da Lei 8.009/90. 
Desta forma, fica claro que a impenhorabilidade beneficia somente um imóvel, desde que destinado a moradia permanente. Enfrentando o caso da pluralidade de domicílios e residências, o legislador estabeleceu a proteção ao imóvel de menor valor, exceto se, voluntariamente, tenha sido instituído bem de família sob modelo do artigo 1.711 e seguintes, do Código Civil. Neste caso, então, este será o bem de família imobiliário e voluntário, deixando, em consequência, de existir o instituído pela Lei ora em estudo.

A impenhorabilidade compreende não só o imóvel residencial, urbano ou rural, em que se assenta a construção, as plantações e as benfeitorias de qualquer natureza, mas também todos os equipamentos, inclusive os destinados ao uso profissional, com exceções das hipóteses tratadas no próximo capítulo.

Desta forma, o terreno e a construção sobre ele edificada e as demais acessões são impenhoráveis, assim como as plantações. Também são incluídas as benfeitorias, todas elas, desde as necessárias, úteis e até as voluptuárias. Mais, são impenhoráveis todos os equipamentos, como arados, tratores, eletrodomésticos, bem como os destinados a uso profissional.

A pequena propriedade rural é também impenhorável, não respondendo por débitos oriundos se sua atividade produtiva, conforme dispõe o art. $5^{\circ}$, XXVI, da Constituição Federal. O preceito constitucional é regulamentado pelo parágrafo $2^{\circ}$, do artigo $4^{\circ}$, da Lei em comento, que também determina quanto aos imóveis rurais, quando não enquadrarem no requisito de pequena propriedade, a impenhorabilidade restringir-se-á à sede de moradia, com os respectivos bens móveis.

Mostra-se evidente, assim, o espirito do instituto do bem de família que não se propôs a defender os economicamente fracos, mas sim por a salvo de penhora principalmente bens imóveis, sem qualquer limitação de valor, garantindo o direito à moradia. Sendo residencial o imóvel, estará protegido.

Seguindo na análise do artigo $1^{\circ}$, parágrafo único, em sua parte final há disposição no sentido de que restam impenhoráveis também os móveis que guarneçam a casa, desde que quitados. A referência é genérica aos móveis que guarnecem a residência, deixando à casuística estabelecer o que seja considerado supérfluo e o que possa ser excluído da execução, nos moldes do capítulo seguinte. O emprego da palavra casa deve ser interpretado como o contexto de residência, para não excluir outras formas de moradia, como apartamentos. Quanto a expressão “desde que quitados", também não foi utilizada de maneira precisa, pois se os móveis não forem de propriedade de qualquer integrante da entidade familiar, não podem ser penhorados. 
Vale citar, ainda, a proteção dos bens móveis dos considerados possuidores de imóveis, como, por exemplo locatários e comodatários. A lei põe a salvo de penhora os bens móveis que guarnecem o imóvel locado e que pertencem ao locatário. Dispõe o parágrafo único, do artigo $2^{\circ}$ da Lei 8.009/90: "No caso de imóvel locado, a impenhorabilidade aplica-se aos bens móveis quitados que guarneçam a residência e que sejam de propriedade do locatário, observado o disposto neste artigo".

Sendo assim, a proteção recai sobre bem móvel próprio do casal ou entidade familiar, ainda que guarneçam imóvel alheio. Nota-se a previsão de um bem de família móvel legal, pois é constituído pela lei, independentemente da vontade das partes, sendo de igual forma norma de ordem pública.

Entretanto, partindo de uma interpretação literal do parágrafo único em análise, percebese que a proteção não é completa, abrangendo somente os casos de locação e deixando de fora a proteção dos demais possuidores de imóvel alheio, como no caso do comodatário, compromissário comprador e usufrutuário. Deve-se levar em conta a intenção do legislador de proteger a família e garantir um mínimo existencial, estendendo a proteção aos móveis destas demais modalidades de possuidores, como fez o Superior Tribuna de Justiça ao entender a proteção ao único imóvel que está em usufruto (STJ, REsp 950.663/SC, 4ª Turma, Rel Min Luiz Felipe Salomão, j. 10.04.2012).

\section{Exceções à Impenhorabilidade}

Visto a abrangência da impenhorabilidade do bem de família legal, passa-se a elucidar as hipóteses de relativização desta impenhorabilidade, ou seja, as causas em que não haverá proteção conferida pela Lei 8.009/90.

De início, o artigo $2^{\circ}$ dispõe que os veículos de transporte, obras de arte e adornos suntuosos estão excluídos da impenhorabilidade.

Quanto aos veículos de transporte, ressalta-se que há, em alguns imóveis, veículos de transporte que são necessários à exploração da atividade que proporciona a subsistência da família e que não foram excepcionados, como barcos de pessoas ribeirinhas, charretes e outros veículos de tração animal etc. Entende-se que esses veículos de transporte, destinados a exploração do bem imóvel principal, não devem integrar as exceções ora estudadas, pois possuem natureza de bens imóveis, acessórios ao principal, por força do artigo 79, do Código Civil. Nessa linha, Maria Helena Diniz assevera que quando a coisa for colocada "a serviço do 
imóvel e não da pessoa", esta imobilização é forma de ficção legal para se evitar que certos móveis, acessórios do imóvel, sejam separados deste. ${ }^{6}$

Sob uma perspectiva ampliada acerca da exceção à impenhorabilidade dos veículos de transporte e levando em consideração o requisito de que o imóvel deve ser residencial, também ficam excluídas da proteção as vagas de garagem que possuem matrículas independentes do imóvel principal. É o teor da Súmula 449 do Superior Tribunal de Justiça, segundo a qual “A vaga de garagem que possui matrícula própria no registro de imóveis não constitui bem de família para efeito de penhora”.

A súmula é alvo de críticas por parte da doutrina, que argumenta, de forma geral, que há quebra do princípio da gravitação, de modo que, se impenhorabilidade atinge o imóvel principal, deve atingir também a vagada garagem, acessória, independentemente de sua autonomia no registro de imóveis. ${ }^{7}$ Além disso, a falta de garagem pode atingir a funcionalidade do imóvel, principalmente em grandes cidades. Some-se ao fato de o artigo $1.331, \S 1^{\circ}$, do Código Civil, proibir a alienação ou locação das vagas para terceiros, estranhos ao condomínio, salvo autorização expressa na convenção, o que é raramente encontrado, levando ao esvaziamento econômico desta situação.

Também com base artigo $2^{\circ}$, a jurisprudência é pacífica no sentido de que os aparelhos eletrodomésticos não são penhoráveis por conta da proteção garantida aos móveis que guarnecem o imóvel residencial, mas há um limite de que os móveis devem ser necessários à família, excluindo-se da proteção os que se mostram voluptuários e que se aproximam da suntuosidade e da ostentação. Essa valoração há de ser feita casuisticamente, sempre tendo em mente que o objeto da proteção desta lei é resguardar a dignidade da família e não a proibição da suntuosidade e ostentação. Neste contexto, há julgado que considerou uma televisão supérflua, determinando sua penhora e, por outro lado, decisão que considerou o mesmo aparelho como objeto necessário e, portanto, livre de execução. O Superior Tribunal de Justiça vem considerando impenhoráveis, por serem necessários ao conforto mínimo das famílias, televisores, aparelhos de som, geladeiras e máquinas de lavar roupa. A título de exemplo, podemos citar uma decisão da Corte Superior, segundo a qual "A impenhorabilidade proclamada pela Lei $\mathrm{n}^{\circ} 8.009 / 90$ objetiva proteger bens patrimoniais familiares essenciais à habitabilidade condigna. $\mathrm{O}$ favor compreende o que usualmente se mantém em uma residência

\footnotetext{
${ }^{6}$ DINIZ, Maria Helena. Curso de Direito Civil Brasileiro: Teoria Geral do Direito Civil. 18. ed. São Paulo: Saraiva, 2012.

${ }^{7}$ TARTUCE, Flávio. Manual de Direito Civil: Volume Único. 6. ed., rev., atual. e ampl. São Paulo: Método, 2016.
} 
e não apenas o indispensável para fazê-la habitável” (STJ, AREsp 592713/SP, Decisão Monocrática, Rel. Min. Luis Felipe Salomão, j. 14/10/2014, Dje 21/10/2014).

Em seguida, o artigo $3^{\circ}$ da mesma Lei consagra outras exceções à impenhorabilidade.

O inciso I do citado artigo trazia exceção à impenhorabilidade se a penhora fosse fruto de crédito de trabalhadores da própria residência e das respectivas contribuições previdenciárias. Incluíam-se os trabalhadores domésticos e os da construção civil que trabalharam no próprio imóvel, desde que com vínculo de emprego. Segundo entendimento do Superior Tribunal de Justiça, caso o vínculo não fosse verificado, como nos casos de empreiteiro que contratou os empregados para construir o imóvel, a exceção não se aplicaria. Ressalta-se, porém, que o inciso em análise foi revogado expressamente pelo Lei Complementar 150 de 2015, responsável por regulamentar os direitos dos trabalhadores domésticos, fazendo o direito à moradia prevalecer sobre créditos trabalhistas de qualquer natureza.

O inciso seguinte estabelece a exceção à impenhorabilidade se a penhora decorrer de ação movida por titular do crédito decorrente de financiamento destinado à construção ou aquisição do imóvel, no limite dos créditos e acréscimos decorrentes do contrato. Nestes casos, subsiste a impenhorabilidade caso o crédito não se destine ao próprio imóvel.

A exceção trazida pelo inciso III é relativa aos créditos decorrentes de pensão alimentícia. Como é cediço, existem três modalidades de alimentos: convencionais, legais e indenizatórios, sendo que a exceção deve recair sobre todas elas. Quanto à última modalidade, não é pacífica a sua inclusão no rol das exceções, existindo corrente que purga pela não incidência desta exceção, argumentando que somente se incluiria os alimentos decorrentes de laços familiares (convencionais e legais), excluindo os decorrentes de atos ilícitos, tese a qual não se filia pelo fato de não existir a exceção alegada no inciso em análise. Neste sentido, o STJ já decidiu no

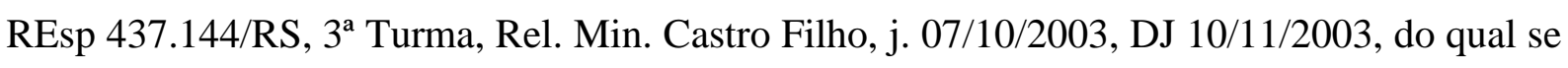
extrai: “O comando do artigo $3^{\circ}$, III, da Lei $n^{\circ} 8.009 / 90$, excepcionando a regra geral da impenhorabilidade do bem de família, também se aplica aos casos de pensão alimentícia decorrente de ato ilícito - acidente de trânsito em que veio a falecer o esposo da autora -, e não apenas àquelas obrigações pautadas na solidariedade familiar, solução que mostra mais consentânea com o sentido teleológico da norma(...)”. No ano de 2015, o referido inciso foi alterado pela Lei 13.144/15, passando a fazer menção de proteção aos direitos do coproprietário que, em união estável ou casamento, figure ao lado do devedor, ou seja, a impenhorabilidade prevalece quando há comunhão, sobre o imóvel, do devedor com companheiro ou cônjuge. Nota-se que a alteração foi desnecessária, vez que, de acordo com as regras que regulam os regimes de bens, a meação do companheiro e do cônjuge já era protegida. 
Seguindo, inclui o inciso IV exceção para cobrança de impostos, predial ou territorial, taxas e contribuições devidas em função do imóvel familiar. Desta forma, o imóvel familiar não fica isento de penhora para cobranças de dívidas originadas em obrigações propter rem ou ambulatórias.

No caso de execução de hipoteca sobre o imóvel oferecido como garantia real pelo casal ou pela entidade familiar, a princípio, o inciso V da citada Lei 8.009/90 também não faz incidir a garantia legal ora estudada. É firme o entendimento doutrinário de que a hipoteca deve ser constituída em favor dos cônjuges ou entidade familiar para que haja a penhora do imóvel, não incidindo a exceção em casos, por exemplo, de hipoteca oferecida por um dos cônjuges para garantir dívida de empresa individual (STJ, REsp 1.324.107/SP, Rel. Min. Nancy Andrighi, 13/11/2012). Além disto, este inciso não alcança a pequena propriedade rural, para não ferir as disposições constitucionais do art. $5^{\circ}$, XXVI.

O próximo inciso, de número VI, aduz que a impenhorabilidade não ocorrerá se o imóvel for adquirido como produto de crime ou para execução de sentença penal condenatória de ressarcimento, indenização ou perdimento de bens.

Outra exceção, disposta no inciso VII do artigo $3^{\circ}$, introduzida pela Lei 8.245/91 (Lei de Locação), dispões que o imóvel familiar será penhorado para cobrança de obrigação decorrente de fiança concedida em contrato de locação de imóvel urbano. Há, em relação a este dispositivo, divergência doutrinária e jurisprudencial sobre sua inconstitucionalidade. Muitos Tribunais, ao redor do Brasil, se filiam a tese da inconstitucionalidade, argumentando que o dispositivo lesaria a isonomia e a razoabilidade, vez que o fiador perderia o seu imóvel, ao passo que o locatário, devedor principal, não perderia, ferindo, assim, a proteção da moradia conferida pelo art. $6^{\circ}$ da Constituição Federal. Não obstante, o Supremo Tribunal Federal decidiu, no ano de 2006, pela sua constitucionalidade, seguido pelo Superior Tribunal de Justiça instado a manifestar-se em sede de incidente de recursos repetitivos, culminando na Súmula 549: "É válida a penhora de bem de família pertencente a fiador de contrato de locação".

Para finalizar a análise das hipóteses de exceções estabelecidas na Lei 8.009/90, trataremos do artigo $4^{\circ}$ e de seu parágrafo $1^{\circ}$. Neste caso, ocorre uma punição do adquirente de má-fé, em estado de insolvência, de imóvel mais valioso que sua residência antiga, para transferir sua residência familiar e, consequentemente, fraudar credores. Então, é facultado ao juiz, em ação movida pelo credor transferir a impenhorabilidade para residência familiar anterior, caso esta não tenha sido alienada, liberando o mais valioso para execução ou anular a 
venda do imóvel da antiga residência, que restará com a mesma impenhorabilidade anterior, liberando o mais valioso para execução.

Vale ressaltar que o Superior Tribunal de Justiça entendeu que este rol de exceções à impenhorabilidade do bem de família é exemplificativo ou numeros apertus. Esta conclusão pode ser retida do REsp1.299.580/RJ, 3 Turma, Rel. Min. Nancy Andrighi, j. 20/03/2012, segundo o qual a proteção do bem de família não pode recair em casos que o devedor atuou de má fé, alienando todos os seus bens e fazendo restar apenas o imóvel de residência. A norma de exceção foi interprestada extensivamente, mas prevaleceu seu sentido social, de eticidade, pois não teria sentido confirmar a exceção causando uma situação flagrante de injustiça e de enfraquecimento da proteção especial objetivada pelo legislador.

\section{Considerações Finais}

O bem de família, como é conhecido atualmente, surgiu no direito norte-americano, com o Homestead Act, objetivando resguardar a moradia de famílias de execuções por dívidas e, por consequência, promover uma expansão territorial para sua região oeste. No Brasil, surgiu no Código de 1916, como modalidade de constituição voluntária, e, mais adiante, introduzida a modalidade de constituição automática pela Lei 8.009/90, sendo uma ferramenta para conferir estabilidade existencial do grupo familiar ao grupamento familiar. Muito se discutiu a respeito da validade da citada Lei, prevalecendo, atualmente, que é constitucional.

Como visto, existem duas espécies de bem de família no ordenamento jurídico brasileiro: o voluntário e o legal. O bem de família voluntário é disciplinado no Código Civil, necessita de escritura pública e registro para ser constituído, o que torna o imóvel impenhorável e inalienável. O bem de família legal não precisa das formalidades mencionadas, opera de pleno direito se satisfeitos seus requisitos (moradia e propriedade do imóvel), não ficado fora do comércio. É um verdadeiro instrumento de garantia do mínimo existencial e de proteção ao núcleo familiar.

O beneficiado pelo bem de família, a par da Lei dispor sobre casal ou entidade familiar, pode ser qualquer pessoa, desde que resida no imóvel e que seja seu proprietário. Considera-se, para efeitos legais, impenhorável o imóvel, abrangendo os móveis que o guarnece, com sua benfeitoria e acessões, a sede do imóvel rural, juntamente, também, com seus móveis e se a entidade familiar possuir vários de mesma natureza será considerado o de menor valor. Não podemos nos olvidar que também é conferida proteção aos móveis quitados do possuidor do imóvel. 
Entretanto, a impenhorabilidade encontra um limite legal, sendo exceções à impenhorabilidade as seguintes hipóteses: veículos de transporte, obras de arte, adornos suntuosos, quando a cobrança for relativa a crédito de pensão alimentícia, de impostos e contribuídos devidos em função do prédio, para execução e hipoteca, se adquirido com produto de crime ou para execução de sentença penal, para cobrança de fiança e em caso de aquisição mais onerosa de má-fé, sendo este rol meramente exemplificativo, conforme entendimento jurisprudencial.

\section{REFERÊNCIAS}

AZEVEDO, Álvaro Villaça. Bem de Família. 6. ed. São Paulo: Atlas, 2010.

CREDIE, Ricardo Arcoverde. Bem de família. São Paulo: Saraiva, 2009.

DAVID, Fernando Lopes. Impenhorabilidade do bem de família nos tribunais. São Paulo: Iglu, 1998.

DINIZ, Maria Helena. Curso de Direito Civil Brasileiro: Teoria Geral do Direito Civil. 18. ed. São Paulo: Saraiva, 2002.

Curso de Direito Civil Brasileiro: Direito de Família, 17. ed. São Paulo: Saraiva, 2002. FIORANELLI, Ademar. Usufruto e bem de família: estudos de direito registral imobiliário. São Paulo: Quinta Editorial, 2013.

HIRONAKA, Giselda Maria Fernandes Novaes. Família e Casamento em evolução. Porto Alegre: Editora Síntese, 2009.

LOPES, Miguel Maria de Serpa. Curso de direito civil. 8. ed., Rio de Janeiro: Freitas Bastos, 2016.

MONTEIRO, Washington de Barros. Curso de direito civil. 42. ed. São Paulo: Saraiva, 2014. v. 2.

MARMITT, Arnaldo. Bem de família legal e convencional. Rio de Janeiro: Aide, 1995.

PEREIRA, Caio Mario da Silva. Instituições de Direito Civil. 12. ed. Rio de Janeiro: Forense, 1991. v. I.

TARTUCE, Flávio. Manual de Direito Civil: Volume Único. 6. ed., rev., atual. e ampl. São Paulo: Método, 2016.

VELOSO, Zeno. Código civil comentado. São Paulo: Atlas, 2013. V. XVII.

VENOSA, Sílvio de Salvo. Direito civil: direito de família. 12. ed. São Paulo: Atlas, São 2012. v. 6. 